\title{
COORDINATED MULTIPARAMETRIC CHARACTERIZATION OF ATMOSPHERIC PARTICULATE IN THE CAMPANIA REGION OF ITALY
}

\author{
CARMEN DE MARCO ${ }^{1}$, ANTONELLA BOSELLI ${ }^{2}$, ANDREA D'ANNA $^{3,4}$, \\ GIOVANNI PERILLO ${ }^{5}$, ALESSIA SANNINO $^{6,7}$, GAETANO SASSO $^{1}$, \\ MARIANO SIRIGNANO ${ }^{3,4}$, NICOLA SPINELLI $^{6,7}$ \& XUAN WANG ${ }^{8}$ \\ ${ }^{1}$ ALA Advanced Lidar Applications s.r.l., Italy \\ ${ }^{2}$ Istituto di Metodologie per l'Analisi Ambientale (IMAA) - CNR, Italy \\ ${ }^{3}$ Centro di Servizi Metrologici Avanzati (CeSMA), Italy \\ ${ }^{4}$ Dip. Ingegneria Chimica, Materiali e Produzione Industriale, Università degli Studi di Napoli Federico II, Italy \\ ${ }^{5}$ Wessex Institute of Technology, United Kingdom \\ ${ }^{6}$ Consorzio Nazionale Interuniversitario per le Scienze Fisiche della Materia (CNISM), Italy \\ ${ }^{7}$ Dip. Fisica "E. Pancini”, Università degli Studi di Napoli Federico II, Italy \\ ${ }^{8}$ Istituto Superconduttori, Materiali innovativi e Dispositivi (SPIN) - CNR, Italy
}

\begin{abstract}
A coordinate measurement approach using remote sensing and near surface instruments has been carried out in the Campania region of Italy with the aim to understand as the anthropogenic sources linked to urban activities (waste disposal, vehicle traffic, and domestic heating) can influence the values of airborne particulate matter (PM) measured at ground in this area. The measurement systems used for the experimental campaign are based on different physical principles in order to gain more information about the nature of PM. In particular, traditional sensors based on gravimetric measurements were used together with an Electrical Low-Pressure Impactor to have near surface information about the total mass, the main fractions and the size distribution of PM. A Doppler Lidar system was used to obtain vertical profile of wind speed and direction and a portable Lidar system in elastic configuration was used to have real time information on atmospheric particles optical properties with high spatial and temporal resolution. The combination of measurements from optical remote sensing and advanced in situ instrumentation produced a significant increase in the knowledge of particulate matter, its sources and the processes in which it is involved. In particular, this work highlights the capability of the Lidar approach to expand the knowledge of PM evolution in the atmosphere with respect to other stationary measurement techniques, potentially paving the road to new air quality monitoring systems.
\end{abstract}

Keywords: Lidar, air quality, $P M$.

\section{INTRODUCTION}

Fine particles in the atmosphere have a strong impact on health [1], climate and environment. Elevated concentrations of airborne particulate matter can be associated with anthropogenic and natural processes. The atmospheric pollution, depending on the amount and chemical composition of fine particles, is related to the emission sources and to the atmospheric circulation phenomena responsible for dispersion, transport, transformation and stagnation of pollutants [2].

In recent years, the atmospheric pollution in the region between the Naples and the southwestern part of the Caserta provinces, in Italy, has become so high to induce local administrations to provide an insight into the link between the sources and the high concentrations of fine particles measured at ground by the monitoring networks [3]. These last provide an accurate description of local concentration but cannot give information about the pollution sources. In fact, the concentration of fine particles at ground depends on local phenomena but also the characteristics of the sources located at medium and long distances. Moreover, the comparison between the properties measured at ground levels and along the 
vertical profile can be important to correlate the temporal variability of the measured properties with macroscopic aspects as air mass transport phenomena and exchanges between ground, planetary boundary layer and free troposphere.

To this aim, the University of Naples Federico II in cooperation with local municipalities carried out some explorative measurement campaigns devoted to measure particles properties both at ground and in the atmosphere using both innovative technologies and standard instrumentation. Many experimental techniques have been used simultaneously to discern whether the PM measured in this area are of natural or anthropogenic nature and thus linked to urban activities (waste disposal, vehicle traffic, and domestic heating).

In this paper, we present the first results of the measurements carried out in the area surrounding the waste disposal plant of S. Tammaro (Caserta) and the municipalities of S. Vitaliano (Naples) and Pomigliano d'Arco (Naples) between December 2015 and February 2017.

The paper is organized as follows: Section 2 describes the used methodology and instrumentation. In Section 3 an overview of the performed measurement campaigns is presented, and the data analysis results are discussed. Conclusions are reported in Section 4.

\section{INSTRUMENTS}

The measurement systems used for the experimental campaign are based on different physical principles in order to gain more information about the nature of PM. In particular, traditional sensors based on gravimetric principle were used to have information about the total mass and the main fractions of the PM; a commercial Electrical Low Pressure Impactor from Dekati was used to obtain the entire size distribution of PM from $7 \mathrm{~nm}$ up to $10 \mu \mathrm{m}$; a Doppler Lidar system was used to obtain in real time vertical profile of wind up to 200 meters; finally a Microjoule POrtable Lidar System ( $\mu$-POLIS), developed by ALA srl within the IAMICA project of CNR, was used to have real time information on atmospheric particles optical properties with high spatial and temporal resolution.

\subsection{Lidar for aerosol monitoring}

A Lidar (Light detection and ranging) system represents one of the most efficient methods in the atmospheric studies, being able to give reliable 4D (space and time) information on particles distributions, their optical properties and microphysical characterization with high spatial and temporal resolution [4].

The Lidar system named $\mu$-POLIS (Microjuole POrtable LIdar System) used in the performed measured campaigns is an innovative instrument developed by ALA (Advanced Lidar Applications srl) a spinoff company of both the University of Naples Federico II and the National Research Council (CNR). $\mu$-POLIS is a compact and portable system with high performance and simple mode of operation, working in the eye-safe region. The Lidar device is equipped with a laser of $1 \mathrm{KHz}$ repetition rate and average optical power of $0.04 \mathrm{~W}$ at $355 \mathrm{~nm}$. The receiving system is based on a $20 \mathrm{~cm}$ Ritchey-Chrétien telescope and is designed to detect both the elastic $\mathrm{S}$ and $\mathrm{P}$ polarized components of the backscattered radiation. $\mu$ POLIS is equipped with a swivelling system, and with a software for automatic continuous measurement and Lidar data analysis. The main features of the Lidar $\mu$-POLIS are summarized in Table 1. 
2.2 Lidar Doppler for wind profiles measurements

A Leosphere WindCube WLS7 v2 system was used to perform measurements of wind speed and direction along the vertical profile.

Table 1: Characteristics of the $\mu$-POLIS system.

\begin{tabular}{|l|c|}
\hline \multicolumn{2}{|c|}{$\mu$-POLIS FEATURES } \\
\hline Type & Passive Q-switch \\
\hline Wavelength & $355 \mathrm{~nm}$ \\
\hline Repetition Rate & $1000 \mathrm{~Hz}$ \\
\hline Energy & $40 \mu \mathrm{J}$ \\
\hline Telescope Diameter & $20 \mathrm{~cm}$ \\
\hline Telescope Focal Length & $500 \mathrm{~mm}$ \\
\hline Field of View & $2 \mathrm{mrad}$ \\
\hline Angular Scanning & Manual \\
\hline \multicolumn{2}{|c|}{ SAMPLING } \\
\hline Channels & 2 \\
\hline Depolarization Channels & yes \\
\hline Temporal Resolution & $1 \mathrm{~min}$ \\
\hline Spatial Resolution & $7.5 \mathrm{~m}$ \\
\hline Range & $(150 \mathrm{~m}-15000 \mathrm{~m})$ \\
\hline \multicolumn{2}{|c|}{-1 OLIS EXTERNAL FEATURES } \\
\hline Dimension & $35 \times 35 \times 35 \mathrm{~cm}$ \\
\hline Weight & yes \\
\hline Eye-Safe
\end{tabular}

Table 2: Characteristics of the WindCube system.

\begin{tabular}{|c|c|}
\hline \multicolumn{2}{|c|}{ WindCube FEATURES } \\
\hline Wavelength & $1540 \mathrm{~nm}$ \\
\hline Repetition Rate & $30000 \mathrm{~Hz}$ \\
\hline Pulse duration & $200 \mathrm{~ns}$ \\
\hline \multicolumn{2}{|c|}{ SAMPLING } \\
\hline Max Sampling Quote & 12 \\
\hline Sampling Data Frequency & $1 \mathrm{~s}$ \\
\hline Spatial Resolution & $20 \mathrm{~m}$ \\
\hline Measurable speed (min.) & $0 \mathrm{~m} / \mathrm{s}$ \\
\hline Measurable speed (Max.) & $55 \mathrm{~m} / \mathrm{s}$ \\
\hline Speed Accuracy & $0.1 \mathrm{~m} / \mathrm{s}$ \\
\hline Direction Accuracy & $2^{\circ}$ \\
\hline Range & $40 \mathrm{~m}-290 \mathrm{~m}$ \\
\hline \multicolumn{2}{|c|}{ WindCube Data } \\
\hline Data Format & Zipped ASCH \\
\hline Data Transfer & LAN/3G/Satellite \\
\hline
\end{tabular}


The system, based on a heterodyne detection, is able to acquire data on 12 programmable altitude in the range of 40-290 metres, with a spatial resolution of 20 metres and a sampling rate programmable between 1 s to 10 minutes.

The Doppler Lidar device is equipped with an internal GPS system and, taking the North direction as a reference, sends 4 sequential beams in the cardinal directions in a $28^{\circ}$ conical aperture and a fifth beam in the Zenith to measure the vertical component of the wind speed. [5] The main features of the WindCube are summarized in Table 2

\subsection{Electrical Low-Pressure Impactor (ELPI)}

Ground particle size distributions have been measured by an Electrical Low-Pressure Impactor (ELPI, Dekati Ltd., Kansagala, Finland). The ELPI is a particle size spectrometer for real-time monitoring of aerosol particle size distributions. The instrument is composed by a corona charger, a 12-stage cascade low-pressure impactor and a multichannel electrometer, which allows covering the entire measurement size range from $30 \mathrm{~nm}$ to 10 $\mu \mathrm{m}$. An extra filter stage was added to extent the measurement size range down to $7 \mathrm{~nm}$. The charged particles are collected on the 13 collection plates, and the current intensity value of each channel, which is proportional to the number of particles collected, is converted into particle aerodynamic size distribution using relationships describing particle size dependent properties of the charger and the impactor stages. The instrument sample flow is $10 \mathrm{~L} / \mathrm{min}$. Measurement data were then processed by the ELPI XLS4.05 software (Dekati Ltd.). An overall dilution ratio of 5 was used for measurements. This value is above the critical dilution ratio to prevent particles coagulation.

\section{MEASUREMENT CAMPAIGNS}

Coordinated measurement campaigns using traditional sensors and innovative instruments were carried out in the period between December 2015 and February 2017 in San Tammaro (Caserta), San Vitaliano and Pomigliano D'Arco (Naples) towns.

The performed measurements and the obtained results are shown below.

\subsection{San Vitaliano (Naples) 28th January 2016}

First exploratory measurement campaigns were performed on 28th January 2016 in San Vitaliano town, in the Naples suburbs, with the aim to explore the link between the sources and the high concentrations of fine particles measured at ground by the monitoring networks of the Naples municipality.

In the colour map in Fig 1 the time variability of the vertical Lidar profiles is reported, where signal intensity is a function of the particle concentration. As Fig. 1 shows, around 1 kilometer of altitude a persistent cloud layer at the top of the Planetary Boundary Layer (PBL) was visible. During nighttime measurement, the cloud layer lowers from 1000 to 500 meters of altitude as the PBL height is reduced. Consequently, a clear increase of the particles concentration close to the ground level is visible in the same figure. Moreover, in the first 200 meters of altitude larger particles concentration was detected until 14:30 LT on 28th and in the time interval 12:30-15:00 LT on 29th January 2016.

Particles concentration was measured with ELPI from 13:50 of the 28th to 09:30 LT of the 29th January 2016. Particle size distributions measured in San Vitaliano town (Fig. 2) show a bimodal size distribution in number concentration with the prevalence of smaller size particles with diameters of the order of $20 \mathrm{~nm}$ and larger particles with sizes of the order of $200 \mathrm{~nm}$. 


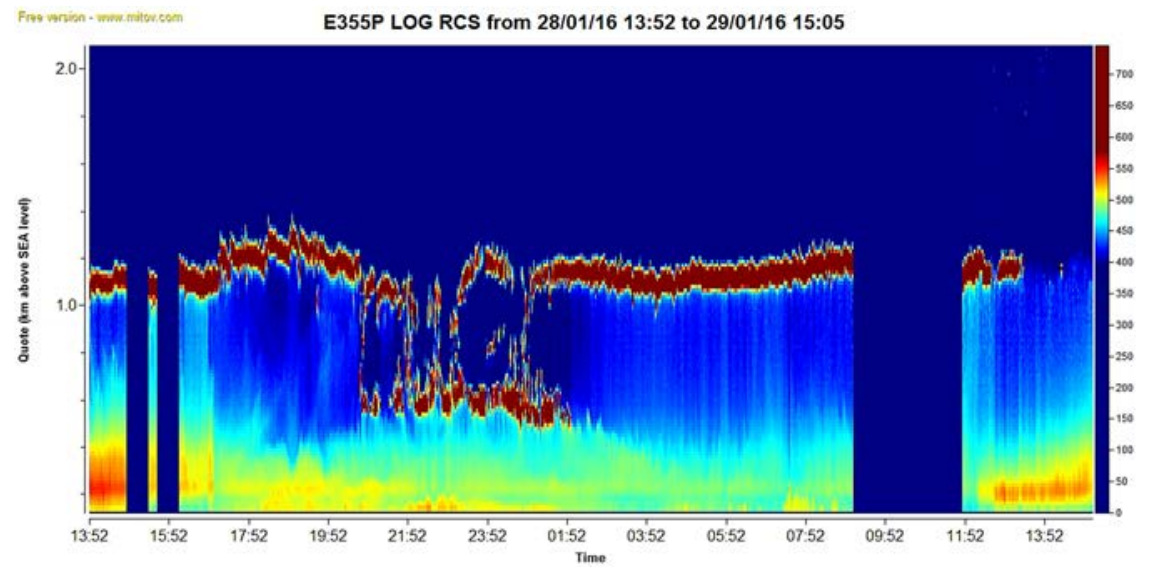

Figure 1: LOG RCS of the Lidar signal at $355 \mathrm{~nm}$ acquired during the San Vitaliano campaign on 28th January 2016.

The size distribution in mass concentration is monomodal with diameters of about 0.5 micron. The same distribution shows also a peak around $2 \mu \mathrm{m}$ and up to $9 \mu \mathrm{m}$ during daytime measurements. The maximum particle concentrations are measured during nighttime in correspondence to the decrease of the Planetary Boundary Layer (PBL) top height.

The bimodal nature of the size distribution suggests the presence of two different sources of emission: combustion processes of gas and liquid fuel (particles with dimension lower than $100 \mathrm{~nm}$ ) and combustion of solid and biomass. Domestic biomass combustion and automotive traffic seem to be the main sources of particulate matter in the San Vitaliano town centre. Moreover, the 2-9 $\mu \mathrm{m}$ peak values could be indicative of larger particles deriving from both erosion and mechanical processes.

The data acquired by $\mu$-POLIS (at lowest quota) and ELPI were compared also with the data granted by ARPAC (Agenzia Regionale Protezione Ambientale della Campania) and related to the $\mathrm{PM}_{2.5}$ and $\mathrm{PM}_{10}$ concentrations, showing (Fig. 3) a good agreement between them.

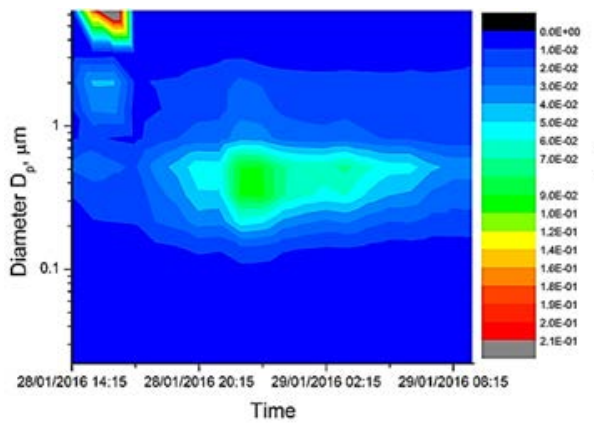

(a)

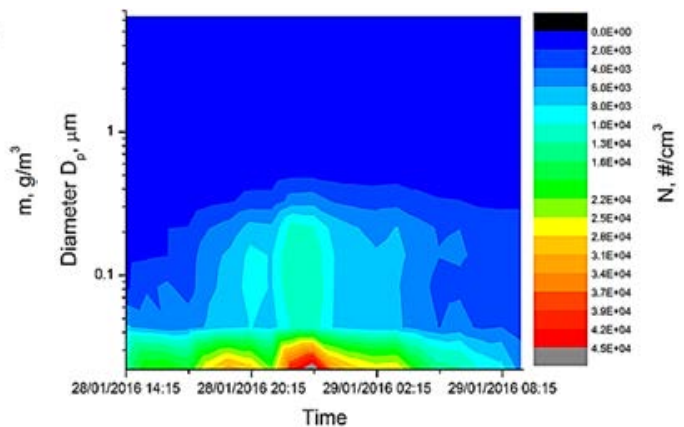

(b)

Figure 2: $\quad$ Particle size distributions measured in San Vitaliano town on 28th January 2016. The distributions are expressed in terms of: (a) mass concentration; (b) number concentration. 


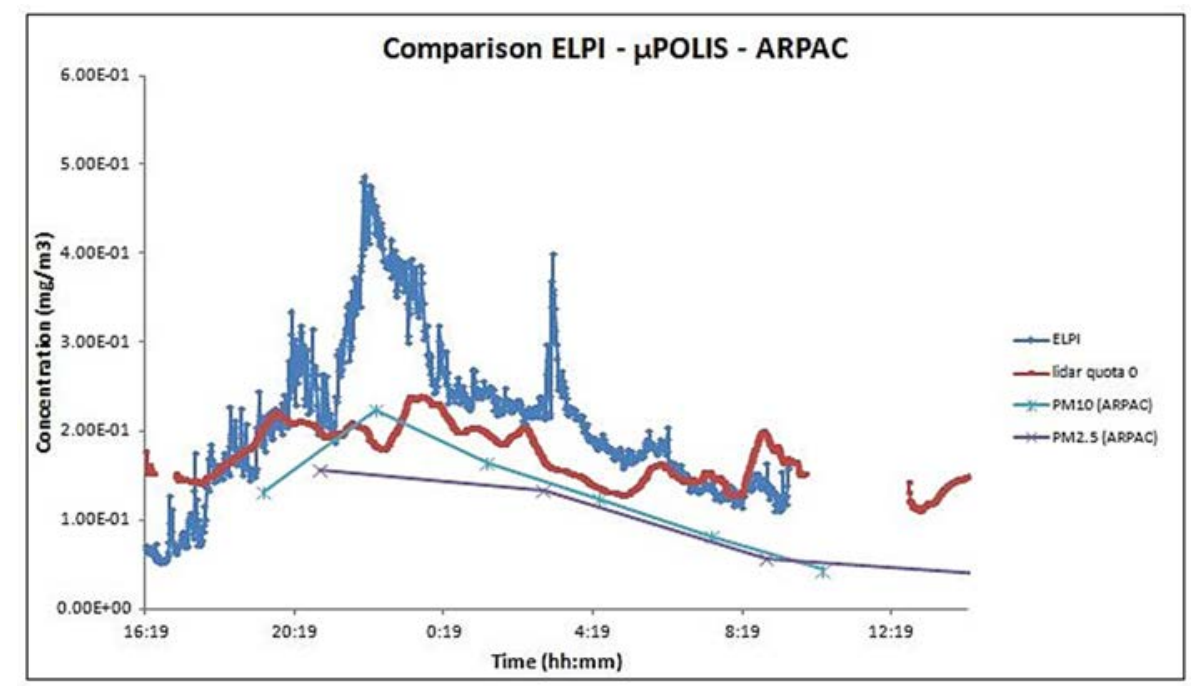

Figure 3: Measurements of: ELPI (dark blue line), $\mu$-POLIS (red line) and ARPAC PM 2.5 (light blue line) and $\mathrm{PM}_{10}$ (violet line) concentrations.

\subsection{San Tammaro (Caserta) landfill - 29th March 2016}

Two exploratory measurement campaigns were performed on 1st December 2015 and 29th March 2016 in San Tammaro (Caserta) where a landfill was chosen for its potential contribution to the pollution releases in the atmosphere. In principle, landfill should present particulate emissions only after special events as disposal or passage of vehicles.

In this area the measurement systems were located in key point near stored waste.

The comparison between the data acquired with the ELPI system and the Lidar systems for atmospheric aerosol and wind profiles, had particular importance in the case of the measurements performed on 29th March 2016 when the devices were located in the same area during a sampling period of about 5 hours which makes it possible to compare a fairly significant amount of data. The aerosol measurements were carried out in vertical direction and with an elevation of $12^{\circ}$ in the waste direction.

The colour maps of Figs 4(a) and (b), reporting the Lidar profiles and the corresponding aerosol depolarization profiles, highlights the presence, over all the landfill area, of an aerosol layer extending until $500 \mathrm{~m}$, which results stable in time; moreover, vertical profiles also show the presence of low clouds in the atmosphere at altitude of about $1 \mathrm{~km}$ whose geometry changed with time.

The almost horizontal measurements like the vertical ones, showed the existence of an aerosol structure within a distance of about $1 \mathrm{~km}$ from the observational area, but the observed structure does not seem related to the landfill presence. In fact, although the laser beam borders on the landfill top (with a pointing angle of $15^{\circ}$ reach $350 \mathrm{~m}$ - minimum distance between the measurement area and the landfill - a height of about $90 \mathrm{~m}$ ) no peaks of concentration are observed. The depolarization profiles, in Fig. 4 (b), highlights several spots of high concentration of particles with not spherical symmetry at low altitude. The time distribution of the measured peaks, suggests a correspondence with the passage of heavy vehicles used for the waste discharge. 


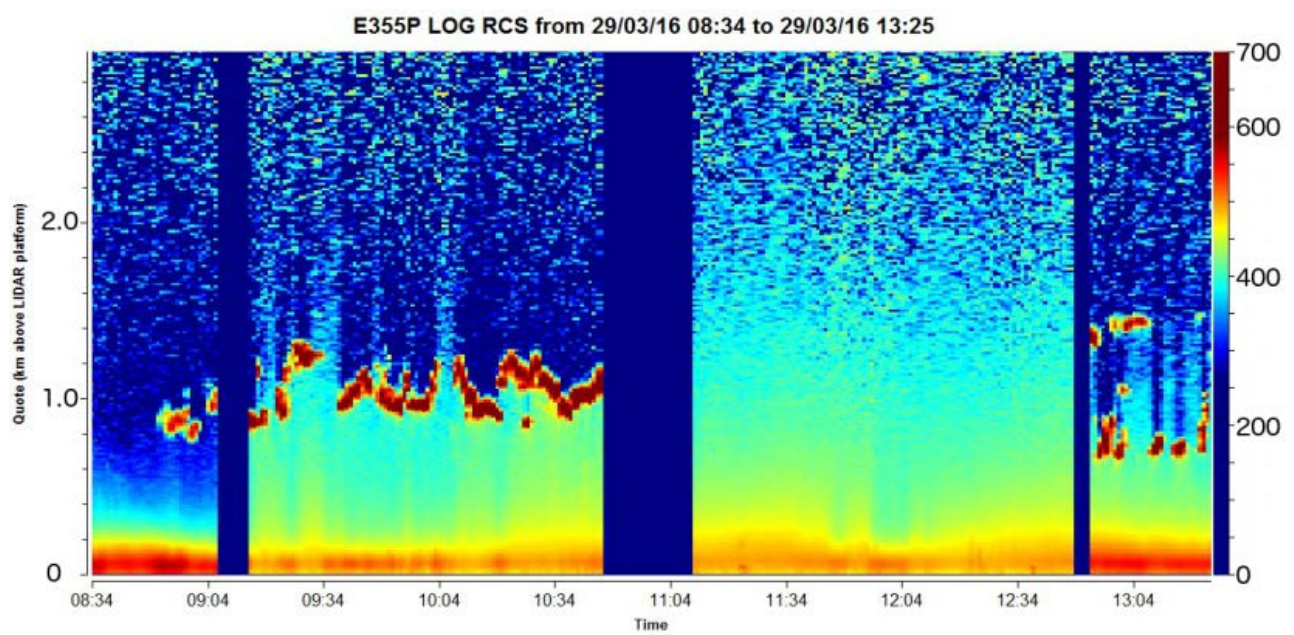

(a)

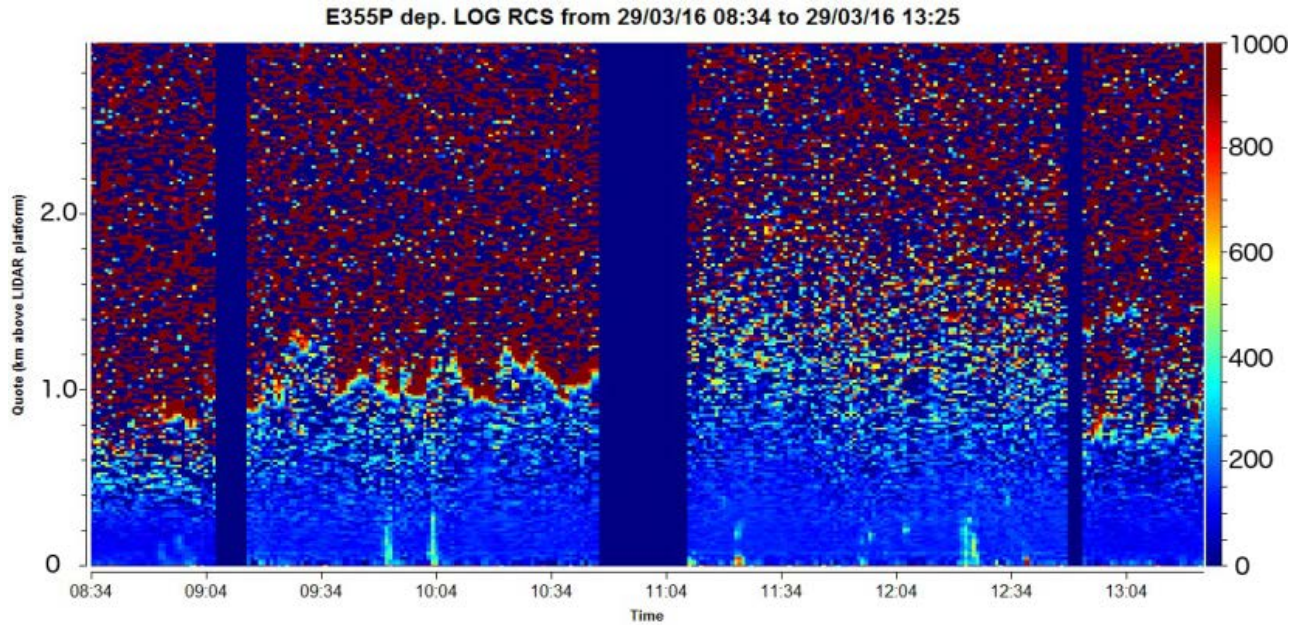

(b)

Figure 4: Data collected in the landfill close to San Tammaro town during 29th March 2016. The third range is referred horizontal measurements $\left(12^{\circ}\right.$ elevation), the others ranges are referred to vertical measurements. (a) Log RCS of Lidar signal at 355nm; (b) Log RCS of Lidar depolarization at 355nm.

Particle size distributions measured during daytime show a monomodal size distribution in number (Fig. 5(a)) concentration with the prevalence of smaller size particles with diameters of the order of 20-30 nm. The size distribution (Fig. 5(b)) in mass concentration is again monomodal but the modal diameter is between 0.9 and 2 micron with a larger mass concentration of particles in the morning before noon and in the afternoon. These maximum particle concentrations are in correspondence of the hours in which a large number of trucks deliver municipal solid wastes. 


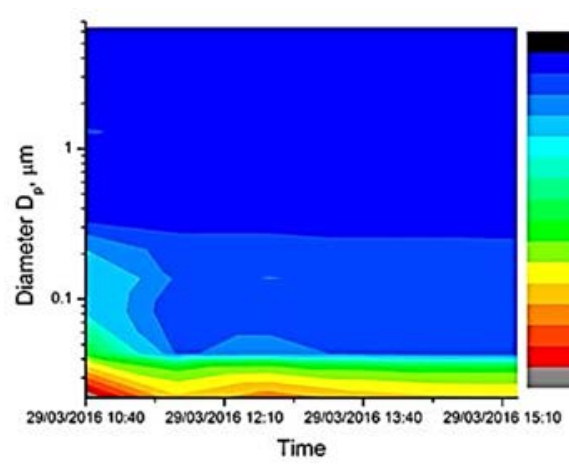

(a)

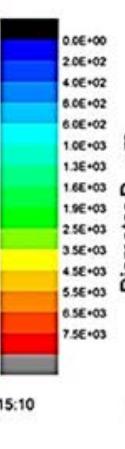

$2903 / 201610: 40 \quad 2903 / 201612: 10 \quad 29 / 03 / 201613: 40 \quad 29: 03 / 201615: 10$ Time

(b)

Figure 5: Particle size distribution measured on 29th March 2016 in S. Tammaro expressed in (a) in number; (b) in mass concentration.

The comparison between the time evolution of the concentration measured with the ELPI and the Lidar $\mu$-POLIS, in Fig. 6 showed data correlated and Bravais-Pearson coefficient $\sigma$ $=0.73$.

The correlation between ELPI data on total mass concentration and Wind Lidar measurements is shown in Fig.7, for wind direction in the range $165^{\circ}-195^{\circ}$ (Fig. 7(a)) and in all the other directions (Fig. 7(b)).

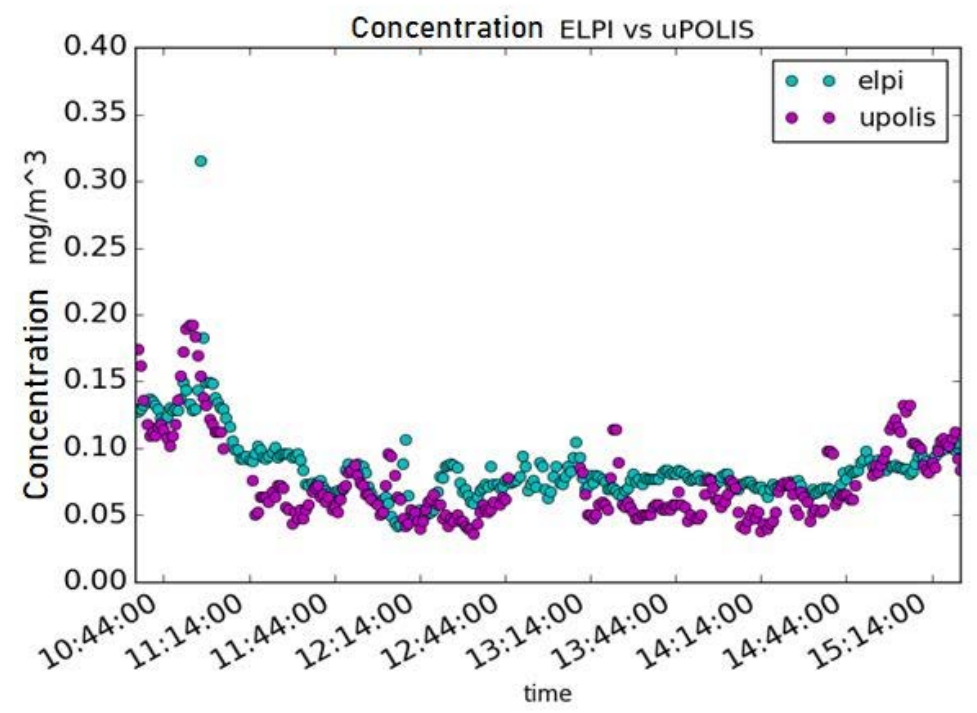

Figure 6: Correlation between ELPI and $\mu$-POLIS obtained by measurements performed on 29th March 2016 in S.Tammaro; a high correlation is observed. 


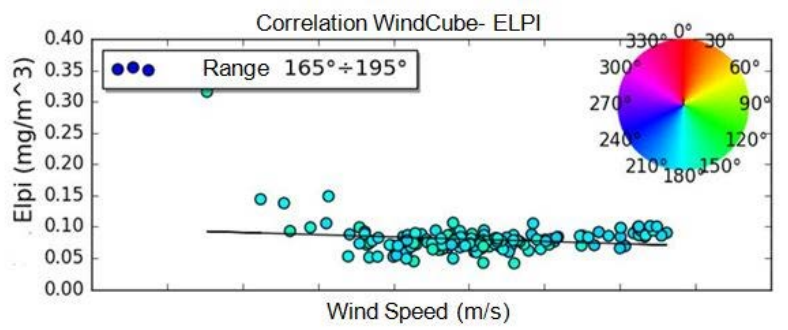

(a)

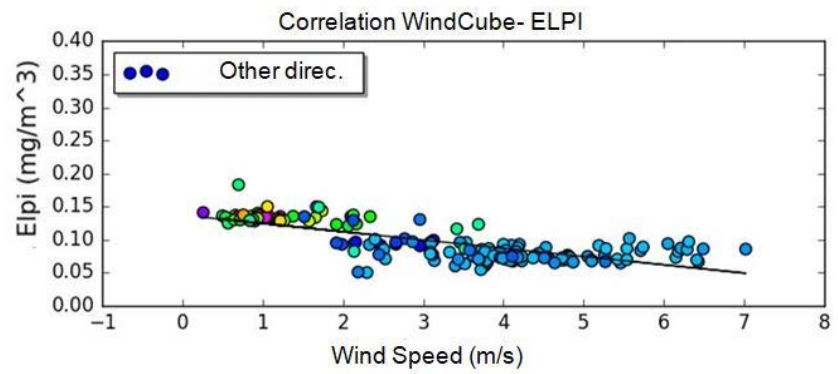

(b)

Figure 7: Correlation between WindCube and ELPI data for the data campaign in the landfill close to San Tammaro in 29th March 2016. (a) In wind direction in the range $165^{\circ}-195^{\circ}$; (b) in all the other directions.

\subsection{Pomigliano D’Arco (Naples), 5th-6th December 2016}

The measurement campaign was carried out in several areas of the town of Pomigliano D'Arco (Naples, Italy) for more than three months. In the present work the results from measurements done on 5th and 6th December 2016 will be shown.

This campaign allowed investigating the atmosphere from a privileged position, the city hall, which is in the middle of the urbanized area. The position of the city hall allowed to perform measurements in three different direction pointing the $\mu$-POLIS system toward the industrial area, the South-West and South-East suburbs. On 5th December, the presence of high concentration of aerosol is observed in the first $500 \mathrm{~m}$ along the laser beam (with a beam inclination of $2^{\circ}$, i.e. $17 \mathrm{~m}$ aloft) in direction of the industrial area. At a distance of about $3500 \mathrm{~m}(120 \mathrm{~m}$ in height) a plume is present. Here two layer are visible in the backscattering profile of Fig. 8(a). The study of the depolarization [6] highlight that the plume is composed by small particles with high level of spherical geometry (water vapour).

On 6th December, as in Fig. 8(b), Lidar profiles with different elevation show the presence of a variable layer of particles up to a distance of $600 \mathrm{~m}$ ( $70 \mathrm{~m}$ in height) and another layer up to $1000 \mathrm{~m}(100 \mathrm{~m}$ in height), changing with time. The depolarization profile shows the presence of small and spherical particles in both layers. The measurements performed pointing to two other directions show a similar trends at lower altitude. This result leads to the hypothesis of a diffused source of particulate spread throughout the municipal territory. 


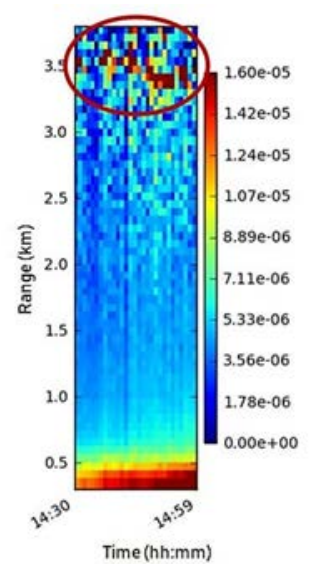

(a)

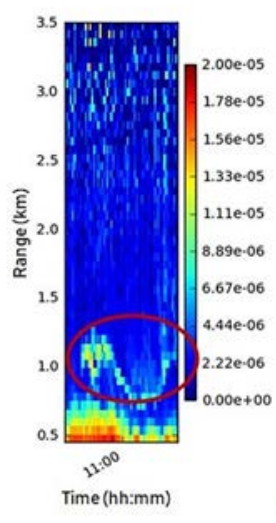

(b)

Figure 8: Backscattering profiles related to the data acquired in Pomigliano D'Arco town in (a) 5th December 2015; and (b) 6th December 2015.

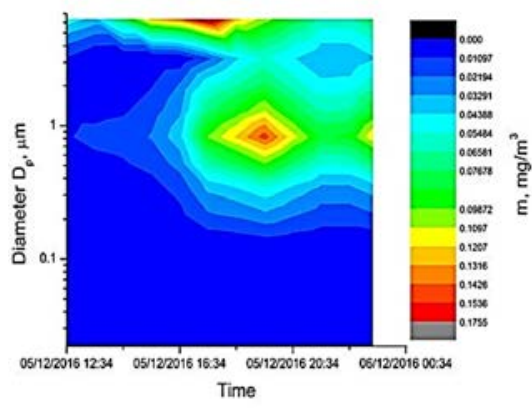

(a)

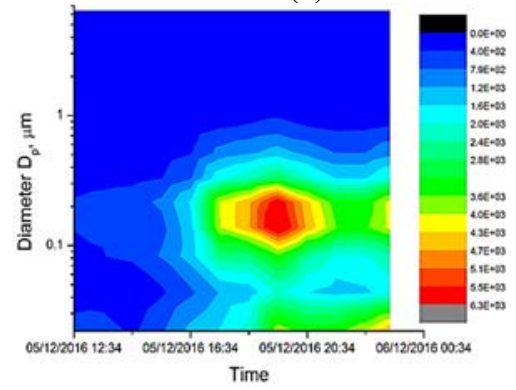

(c)

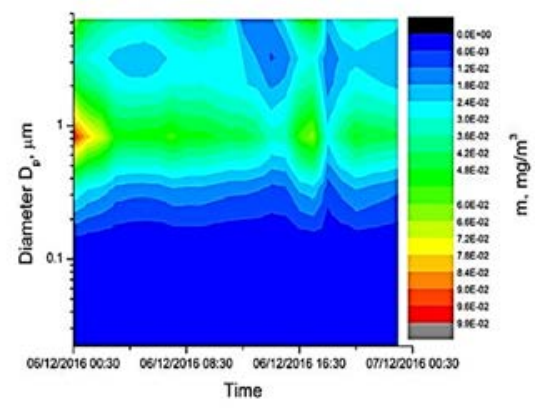

(b)

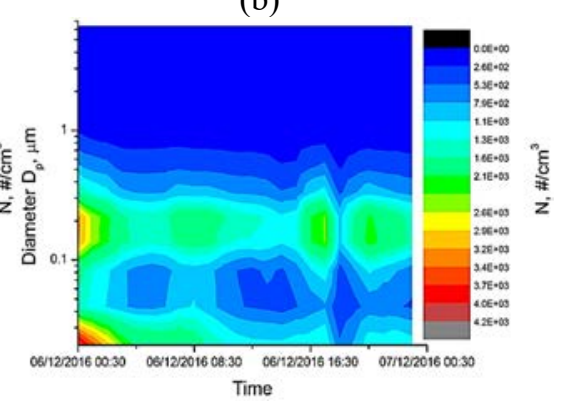

(d)

Figure 9: Particle size distributions measured in Pomigliano city center expressed in terms of mass concentration on the days (a) 5th December 2015; and (b) 6th December 2015. The same data are expressed in terms of number concentration on the days (c) 5th December 2015; and (d) 6th December 2015. 
Particle size distributions measured in Pomigliano city center show a bimodal size distribution in number concentration (Figs 9(c); (d)) with the prevalence of smaller size particles with diameters of the order of 20-30 nm and larger particles with sizes of the order of 100-300nm. The size distribution in mass concentration (Figs 9(a); (b)) is again bimodal but the modal diameters are much larger, i.e. between 0.9 and $2 \mu \mathrm{m}$ and at around $10 \mu \mathrm{m}$. The maximum particle concentrations are measured late in the day in correspondence of the decrease of the planetary boundary layer (PBL).

The ELPI size distributions are quite different from those measured in the waste disposal indicating a different origin for the particles. Higher concentrations are measured in correspondence to lower wind speeds, but they are independent on wind direction.

\section{CONCLUSIONS}

Innovative remote sensing and near surface instruments were used in different measurement campaigns carried out in the Campania region of Italy with the aim to understand how anthropogenic source as waste disposal, vehicle traffic and domestic heating, can influence the values of airborne particulate matter measured at ground level. In particular, traditional sensors based on gravimetric principle were used together with an Electrical Low Pressure Impactor to have near surface information about the total mass, the main fractions and the size distribution of PM; portable Lidar systems for aerosol and wind profiling in the atmosphere were used to obtain real time information on atmospheric particles geometrical and optical properties and wind speed and direction with high spatial and temporal resolution. Although the performed experimental investigation must be considered as preliminary, it clearly shows the degree of information that can be obtained through a monitoring system making use of the synergy between innovative instruments.

The possibility to study the particles spatio-temporal distribution both in the urban area and on a waste disposal site allows a first evaluation of the effectiveness of the method.

The analysis of Lidar profiles confirms the critical situation of the Naples and Caserta provinces, showing not only the high concentration degree of the pollutants near the ground, but also its extension on the whole studied area. Lidar measurement allowed to capture aerosol layering in the atmosphere and to verify how the PBL reduction, involves a confinement of the particulate at ground. Data coming from optical remote sensing and advanced in situ instrumentation were analyzed also correlating the observed results. The Lidar and ELPI combined use make possible to determine the effective dimensions of the particles that were consistent with those deriving from combustion processes typical of domestic heating and vehicular traffic. Particle size distribution in mass and in number allowed to identify different sources of the particles at ground level. Results of the observations highlighted that the landfill is characterized by particulate with a size between 1 and 2 microns (e.g. secondary aerosol). Particles with diameters between 300 and $700 \mathrm{~nm}$ are linked to heavy transport (trucks), while those between 100 and $200 \mathrm{~nm}$ are linked to light traffic.

Finally, this work highlights the capability of the Lidar approach once tested and validated to expand the knowledge on particulate matter monitoring with respect to punctual observations

\section{ACKNOWLEDGEMENTS}

The financial support for ACTRIS in the Seventh Framework Programme under grant agreement No. 262254 are gratefully acknowledged. The authors also acknowledge ARPAC for providing PM data. 


\section{REFERENCES}

[1] Du, Y., Xu, X., Chu, M., Guo, Y. \& Wang J., Air particulate matter and cardiovascular disease: the epidemiological, biomedical and clinical evidence. J Thorac Dis., 8(1), E8E19, 2016.

[2] Hinds, W.C., Aerosol Technology: Properties, Behavior, and Measurement of Airborne Particles, 2nd ed., Wiley-Interscience, pp. 206-315, 1999.

[3] Senior, K. \& Mazza, A., Italian triangle of death, linked to waste crisis. The Lancet Oncology, 5(9), 2004.

[4] Weitkamp, C., Lidar: Range-Resolved Optical Remote Sensing of the Atmosphere, Springer, NY, USA, 2005.

[5] Sathe, A., Mann, J., Gottschall, J. \& Courtney, M.S., Can wind lidars measure turbulence? Journal of Atmospheric and Oceanic Technology, 28, 2011.

[6] Mishchenko, M. \& Sassen, K., Depolarization of lidar returns by small ice crystals: an application to contrails. Geophysical Research Letters, 25(31), pp. 309-312, 1998. 